\title{
A cross-sectional study of oral antibacterial treatment patterns in relation to specific diarrhoeal pathogens in weaner pigs
}

Jensen, Vibeke Frøkjær; Jorsal, Sven Erik Lind; Toft, Nils

Published in:

Veterinary Microbiology

Link to article, DOI:

10.1016/j.vetmic.2017.01.038

Publication date:

2017

Document Version

Peer reviewed version

Link back to DTU Orbit

Citation (APA):

Jensen, V. F., Jorsal, S. E. L., \& Toft, N. (2017). A cross-sectional study of oral antibacterial treatment patterns in relation to specific diarrhoeal pathogens in weaner pigs. Veterinary Microbiology, 203, 18-24.

https://doi.org/10.1016/j.vetmic.2017.01.038

\section{General rights}

Copyright and moral rights for the publications made accessible in the public portal are retained by the authors and/or other copyright owners and it is a condition of accessing publications that users recognise and abide by the legal requirements associated with these rights.

- Users may download and print one copy of any publication from the public portal for the purpose of private study or research.

- You may not further distribute the material or use it for any profit-making activity or commercial gain

- You may freely distribute the URL identifying the publication in the public portal 


\section{Accepted Manuscript}

Title: A cross-sectional study of oral antibacterial treatment patterns in relation to specific diarrhoeal pathogens in weaner pigs

Authors: Vibeke F. Jensen, Sven-Erik L. Jorsal, Nils Toft

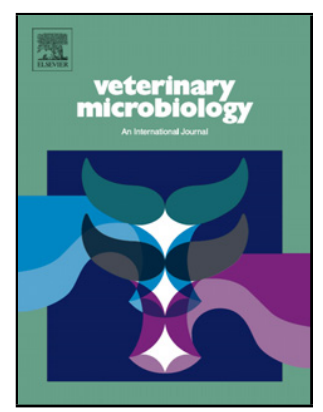

PII: S0378-1135(16)30324-8

DOI: http://dx.doi.org/doi:10.1016/j.vetmic.2017.01.038

Reference: VETMIC 7537

To appear in: VETMIC

Received date: 13-9-2016

Revised date: 28-1-2017

Accepted date: 29-1-2017

Please cite this article as: Jensen, Vibeke F., Jorsal, Sven-Erik L., Toft, Nils, A cross-sectional study of oral antibacterial treatment patterns in relation to specific diarrhoeal pathogens in weaner pigs.Veterinary Microbiology http://dx.doi.org/10.1016/j.vetmic.2017.01.038

This is a PDF file of an unedited manuscript that has been accepted for publication. As a service to our customers we are providing this early version of the manuscript. The manuscript will undergo copyediting, typesetting, and review of the resulting proof before it is published in its final form. Please note that during the production process errors may be discovered which could affect the content, and all legal disclaimers that apply to the journal pertain. 
A cross-sectional study of oral antibacterial treatment patterns in relation to specific diarrhoeal pathogens in weaner pigs

Vibeke F. Jensen $^{\mathrm{a}, \mathrm{b}}$, Sven-Erik L. Jorsal ${ }^{\mathrm{a}}$, Nils Toft ${ }^{\mathrm{a}}$

${ }^{a}$ Section for Veterinary Diagnostics and Scientific Advice, National Veterinary Institute, Technical University of Denmark, Bülowsvej 27, DK-1870 Frederiksberg C, Denmark.

${ }^{\mathrm{b}}$ Corresponding author. E-mail: vfje@ vet.dtu.dk 


\section{Highlights}

- Antimicrobial use should be evidence based and prudent according to WHO guidelines.

- In Danish weaning pigs, tetracyclines were the most frequently used antimicrobials for diahrroea by a substantial margin, irrespective the identified pathogen, including Brachyspira pilosicoli, Lawsonia intracellularis, and E.coli (F4 and F18). Tetracyclines are 2. or 3.rd choice antimicrobial according to the national guidelines

- Increasing compliance with the national treatment guidelines was observed in $14 \%$ of the herds with laboratory finding of B.pilosicoli, suggesting that B.pilosicoli is underdiagnosed based on clinical criteria.

- In herds with moderate-massive amounts of Brachyspira pilosicoli, Lawsonia intracellularis, or E.coli (F4 and F18), between $10 \%$ and $20 \%$ of the herds did not use antimicrobial batch treatment.

- The antimicrobial use per pig appeared to decrease more in herds with negative laboratory results compared to herds with a moderate-massive occurrence of either of the pathogens, but this finding could be related to register data bias. 


\begin{abstract}
According to international guidelines, the use of antibacterials should be evidence based and prudent. This register-based, cross-sectional study investigates the potential effect of laboratory findings on the patterns of antibacterial oral (batch) medication of weaner pigs, and the level of compliance with national guidelines for antibacterial use. The study population includes 1,736 weaner herds ( $\approx 65 \%$ of all Danish weaner pigs) that were subject to laboratory analysis from the National Veterinary Institute on Brachyspira pilosicoli, Lawsonia intracellularis, and E.coli (F4 and F18) in 2014. Antibacterial prescription data were obtained from the national database, VetStat. These showed that antibacterial prescriptions for use in weaner pigs was $8.6 \%$ lower in spring 2015 compared to spring 2014. The antibacterial use per pig tended $(\mathrm{p}=0.08)$ to decrease more in herds with negative laboratory results compared to herds with a moderate or massive occurrence of either of the pathogens. Irrespective of the laboratory findings on diarrhoeal pathogens, tetracyclines were the most frequently used antibacterials by a substantial margin, both 3 months prior to and 2-5 months after laboratory analysis. According to the national guidelines, tetracyclines are the second or third-choice antibacterial for treatment of diarrhoeal pathogens, due to resistance and coresistance patterns. Compliance with the guidelines increased in $14 \%$ of the herds, mostly following identification of B. pilosicoli within the herd. Between $10 \%$ and $20 \%$ of the herds did not use batch treatment, despite the presence of moderate-massive amounts of the pathogens.
\end{abstract}

Keywords: Pigs, diarrhoea, bacterial pathogens, antibacterial choice, evidence-based prescribing 


\section{Introduction}

Strategies to combat the emergence of antibacterial resistance must be targeted at supporting nonantibacterial disease prevention and decreasing non-responsible use both in humans and animals (WHO, 2015). Numerous strategies have been applied to promote the prudent use of antibacterials (ranging from legal restrictions and treatment guidelines to information campaigns), and guidelines for antibacterial use in veterinary practice have been published internationally as well as in individual European countries (Teale and Moulin, 2012). A key step towards prudent antibacterial use is to decide whether the treatment is necessary, or if non-antibacterial prophylactic means should be implemented. In addition, the most appropriate antibacterial should be used. However, the decision to treat and choice of antibacterials may be affected by numerous factors other than professional veterinary knowledge (Busani et al., 2004, Vandeweerd et al., 2012; Gibbons et al, 2013; De Briyne et al., 2013; Coyne et al., 2014).

In Denmark, a number of legal interventions have been implemented in order to promote the prudent use of antibacterials (DANMAP 2010). The vast majority of antibacterials used in the veterinary field are prescribed for pigs and as a consequence, a legal intervention called "The Yellow Card Initiative" was enforced in 2011, which imposes restrictions and preventive measures in the herds with the highest consumption per pig (Anonymous, 2011; Anonymous 2014b). Antibacterials are usually administered to pigs (in particular weaners) per pen or section via feed or water, implying that healthy animals within the pens are also treated (Merle et al., 2012; Callens et al., 2012). However, oral administration appears to be a crucial factor in the risk of antibacterial resistance development (Burow et al., 2014).

Batch treatment is often used for preventive purposes in pigs, but practice and legislation differ amongst the individual European countries (Callens et al., 2012). In Denmark, prophylactic use is illegal, and all antibacterial use is by prescription only, requiring a diagnosis based on veterinary examination of the animal or herd (Anonymous, 2014a). Once a herd diagnosis is established, and if 
potential recurrent disease is indicated, metaphylactic treatment administered by the farmer is allowed - legally defined as treatment "in a well-defined incubation phase" - but only if a Veterinary Health Advisory Contract (VAC) is in place (Anonymous, 2014a). However, the criteria for discontinuing repeated treatment of consecutive batches of pigs are not clear. A British focus group study documented that both farmers and veterinarians found it difficult to decide when to withdraw prophylactic treatments (Coyne et al. 2014). A recent Danish study (Pedersen et al., 2015) found that $84 \%$ of the farmers used some clinical inspection criteria to determine when to initiate treatment, while antibacterials were used systematically on a fixed day post-weaning in $16 \%$ of the herds, suggesting a prophylactic application. Furthermore, recurrent monthly herd-level prescription of the same antibacterial occurs in a large proportion of Danish weaner herds (DANMAP 2008).

According to the WHO action plan on antibacterial resistance (Anonymous, 2015a), evidence-based prescribing and dispensing should be standard practice. Official Danish treatment guidelines for pigs relate to the selection of antibacterials for treatment of specific pathogens (DANMAP 2010), presupposing the identification of a causal agent. However, a recent Danish study indicated only a slight agreement between the veterinarians' clinical aetiological diagnosis and the diagnosis from laboratory examinations for gastrointestinal (GI) bacterial pathogens (Pedersen et al. 2015). Furthermore, diarrhoea may have a non-infectious or viral aetiology (Pluske et al. 2002; ChaseTopping et al. 2007). On $1^{\text {st }}$ June 2014, the Danish Food Authority implemented a new article in the Health Advisory Contracts Order (Anonymous, 2014c) targeting antibacterial group medication, defined as in-feed or water medication of pigs. Laboratory diagnostics became mandatory in relation to the oral treatment of respiratory or GI disease in herds with a Veterinary Health Advisory Contract (VAC), and the veterinarian must sample and submit material from untreated pigs prior to antibacterial group medication. Depending on the laboratory results, the veterinarian must evaluate (and if indicated, rectify) the treatment, and/or submit supplementary samples. Ultimately, if a causal bacterial pathogen is not clearly identified, alternative treatment strategies must be 
considered. The resulting laboratory data provide information on the presence of specific bacterial pathogens at herd level in a large proportion of Danish pig herds.

The objectives of the current investigation were to: 1 ) determine whether the mandatory laboratory testing may have affected antibacterial use; 2) describe and assess the use of antibacterials for oral treatment of diarrhoea in weaner pigs, as well as the potential association with the laboratory findings; 3) evaluate whether the laboratory results were associated with a change in treatment strategy and compliance with the national guidelines for antibacterial treatment.

\section{Materials and Methods}

\subsection{Laboratory data}

According to the legal order (Anonymous, 2014c), a submission of diagnostic samples in relation to the symptoms of GI disease should contain at least faecal samples, gut section or cadavers. The faecal samples must be collected before treatment as either a "sock sample" or a pooled faecal sample. It is often not possible to clearly differentiate between infections with the most common pathogens: Brachyspira pilosicoli (B. pilosicoli), Escherichia coli (E. coli, fimbria type F4 and F18), or Lawsonia intracellularis (L. intracellularis) from clinical symptoms alone (Pedersen et al., 2015), and the legal order therefore recommends analysis for all four pathogens. If the sample is positive for E.coli, antibacterial sensitivity testing of E.coli isolates is recommended. Other bacterial pathogens such as Salmonella spp. or Brachyspira hyodysenteriae might be suspected, though these are unlikely; B. hyodysenteriae is extremely rare in Denmark due to the Danish SPF-system and Salmonella is rarely detected in relation to clinical disease in pigs (Anonymous 2016b). In a recent study of 20 randomly selected herds with outbreaks of diarrhoea, the four previously mentioned bacterial species were the only bacterial pathogens found (Pedersen et al., 2014).

The National Veterinary Institute (NVI) analysed the vast majority of samples that were analysed for the four pathogens in 2014 (Anonymous 2015b). The samples submitted to the NVI for bacterial 
GI pathogen analysis were almost entirely faecal samples - either pooled samples or sock samples. The standard analysis of faecal samples includes quantitative PCR (q-PCR) for B. pilosicoli, E. coli (fimbriae type F4 and F18) and L. intracellularis. Analyses for individual pathogens using other methods were not included in the present investigation due to their sporadic occurrence. The outcomes from the q-PCR on pooled faecal samples were given as a categorical variable with four groups based on the number of copies per gram faeces: massive, moderate or low-grade occurrence and none identified (NI), as given in Table 1. The qPCR analyses were identical for both faecal samples and sock samples, but the initial preparation of the samples differed.

The initial data set contained 3,939 submissions associated with analysis for all four pathogens, some of which were consecutive submissions from the same herd. Second submissions are often due to negative results from the prior submission, so in order to obtain information on the causal pathogen, consecutive submissions were considered together (see further considerations in Section $3.2)$.

\subsection{Herd selection criteria}

All farms in Denmark are identified by a code (CHR-ID) within the Central Husbandry Register (CHR). In this study, a herd was defined as all animals within a given age group on a farm. Herds were included in the analysis when the following criteria were all met:

- Laboratory analysis by q-PCR was performed for all four pathogens for samples with the same submission date in $2014(\rightarrow 3,282$ herds $)$.

- The age group given in the laboratory record related to weaners or was missing $(\rightarrow 2,507$ herds). Laboratory data with no age group recorded were included in this step because analysis aimed at diarrhoeal pathogens was most likely to be performed on weaner pigs if these were present on the farm.

- Weaner pigs were present on the farm according to the CHR $(\rightarrow 1,813$ herds). 
- The herd comprised at least 100 weaner pigs (according to the CHR) by $1^{\text {st }}$ April 2014 and by $1^{\text {st }}$ April $2015(\rightarrow 1,745$ herds $)$.

- A veterinary advisory contract (VAC) was active on $1^{\text {st }}$ June $2014(\rightarrow 1,736$ herds), as the legal order was only relevant for herds with an active VAC from this date.

Farms with fewer than 100 weaners were omitted because they were likely to be sow herds, where a small and often variable number of pigs remain on the farm after weaning. Only farms with a VAC were included because legal Order 534 (2014) was aimed at these farms due to their otherwise more liberal access to antibacterials compared to other farms. The vast majority of the Danish pigs are produced on farms with a VAC.

\subsection{Antibacterial prescription data}

Around $98 \%$ of the antibacterials used in weaners were administered through feed or drinking water, of which $75 \%$ were prescribed for intestinal disease (Jensen et al., 2014). Data from January 2014-June 2015 were extracted to obtain records of antibacterial use in the 3-month period prior to the first herd being tested (for testing of Hypothesis 2), and to include the 3-month periods spanning April-June in both 2014 and 2015 (for testing of Hypothesis 1). Data on all prescriptions of oral antibacterial medicines prescribed for weaners were extracted from the Danish veterinary prescription database, VetStat (Stege et al., 2003). VetStat covers the whole country and contains detailed information about all veterinary prescriptions for therapeutic medicines at species level. In the case of production animals, each prescription is represented by a record including information on the date of purchase, product identity and quantity, identity of the prescribing veterinarian, CHRID, targeted species, age group and disease category. VetStat data are generally considered to cover more than $99 \%$ of the total prescribed amounts of antibacterials for veterinary use (DANMAP 2001). 
In the first step, all records relating to the sale of oral antibacterial medicines prescribed for weaner pigs in the 1,736 study farms between January 2014 and July 2015 were extracted. The amounts of the antibacterial medicines were converted into the number of defined standard doses for a pig with a body weight of $15 \mathrm{~kg}$ (Animal Daily Dose, $\mathrm{ADD}_{15}$ ). The standard doses defined by the Danish Food Administration for the Yellow Card Initiative were applied in this study (Anonymous, 2014b).

\subsection{Study design}

This study included all herds that met the selection criteria. The herds were initially grouped according to the laboratory findings (Table 1). Using the same cut-off values for the two tests, the laboratory results were transformed to a variable with three groups: negative, low-grade and moderate-massive (Table 1). We decided not to differentiate between E.coli F4 and E.coli F18, because the recommendations in the official guidelines are given at bacterial species level. The herds were grouped into nine diagnosis groups based on the collective laboratory analyses for the herd (Table 1).

Two hypotheses were investigated:

- Antibacterial use would be reduced in herds where none of the four bacterial pathogens could be identified in the laboratory (H1).

- The choice of antibacterial agent would be adjusted towards a higher compliance with the official guidelines in the months following laboratory diagnosis $(\mathrm{H} 2)$.

With regard to the antibacterial prescription, it was assumed that the laboratory diagnosis would be followed by a lag phase of some months before adjustments to the treatment strategies and disease management would be fully implemented.

\section{Hypothesis $1(\mathrm{H} 1)$ :}

In general, the use of antibacterials in Danish weaner pigs decreased considerably during 20142015, so an overall decrease in antibacterial use could be expected in the study herds. In order to 
address H1, we wanted to investigate whether negative laboratory results were associated with larger decreases in antibacterial prescription compared to cases where pathogenic levels of the bacteria were found. The laboratory findings were cathegorized into three groups (negative; lowlevel; and moderate-massive levels of the pathogens) because the pathogenicity of E. coli (F4 and F18), B. pilosicoli and L. intracellularis at low levels ( $<10^{4.5}$ per gram faeces) was questionable (Pedersen et al., 2014). In order to investigate whether a negative diagnosis caused a decrease in antibacterial use over time, it was necessary to have a control group comprising herds for which the result of the laboratory diagnosis would not be expected to motivate a reduction in antimicrobial use. Herds with moderate-massive occurrence of any of the pathogens were used as a control group because this is mostly associated with diarrhoea, and the finding of a pathogenic level of the bacteria would not prompt the discontinuation of medication. Herds with low levels of the pathogens were omitted because the significance was questionable, and consequently the effect on antimicrobial use was unpredictable.

All oral antibacterial use was included in this part of the study, because antibacterials for oral use in weaners are almost exclusively $(\sim 75-80 \%)$ used for the treatment of diarrhoea; even oral antibacterials prescribed for other indications might be used for GI disease treatment by the farmer. H1 was investigated by comparing the antibacterial use over the period March-May 2014 (before the legislation was implemented) to that of March-May 2015. The latter period was chosen to limit the effect of seasonal variation in antibacterial prescription. In addition, changes in disease management were expected to affect antibacterial use until spring 2015 on farms that received the final laboratory diagnosis in the last quarter of 2014.

The treatment incidence (TI) was estimated for both periods based on the number of weaner pigs (n) registered in the CHR by $1^{\text {st }}$ April in the same year, as:

$$
T I=\frac{\# \text { ADD15 }}{\text { weaning pig produced }}=\frac{4 * \mathrm{nADD} 15}{n * r}
$$


where $\mathrm{nADD}_{15}$ is the number of standard doses prescribed within the respective 3-month period and $r=6.64$ is the number of rotations per year in the weaner section. The number of rotations was estimated from 2014 productivity data from the Pig Research Centre (Jessen, 2015).

The TI was also calculated at national level (using data on the number of breeding sows from Statistics Denmark) in order to validate the TI as calculated for the study herds, and to evaluate whether herds with moderate-massive pathogen load constituted a representative control group. The number of weaners produced during March-May 2014 and March-May 2015 was estimated as:

$$
\text { weaners produced }=\mathrm{N}_{\text {sows }} *\left(\mathrm{w}_{\text {sow }} * 91 \text { days } / 365 \text { days }\right) *\left(1-\text { mortality }_{\mathrm{w}}\right)=7.4 * \mathrm{~N}_{\text {sow }}
$$

where $\mathrm{N}_{\text {sows }}$ is the number of breeding sows on $1^{\text {st }}$ April in the given year (Statistics Denmark, $2016) ; \mathrm{w}_{\mathrm{sow}}=30.6$ weaned piglets/ sow-year in 2014 ; mortality $_{\mathrm{w}}=2.9 \%$ for weaner pigs from weaning to $30 \mathrm{~kg}$ body weight in 2014 (Jessen, 2015). The national TI was subsequently estimated for each 3-month period, including all oral antibacterial prescriptions for weaners.

\section{Hypothesis $2(\mathrm{H} 2)$}

The objective was to investigate whether the choice of antibacterials (i.e., whether the prescription pattern for treatment of GI disease) changed depending on the laboratory diagnosis. Only antibacterials prescribed for oral treatment of GI disease were included in this part of the study, since the main focus was on the choice of antibacterial for treating GI disease. A small number of prescription records that lacked an indicated target disease were also included as it was deemed that GI disease was the most likely reason for treatment.

In theory, antibacterial prescription patterns at herd level show an infinite variation. However, in most herds, only one antibacterial agent is regularly prescribed for oral use over extended periods of time (DANMAP 2008). In most cases, a single antibacterial agent makes up the vast majority of total antibacterials prescribed for a given farm, and we refer to this antibacterial class as the principal antibacterial for that farm. In some farms, more antibacterials are used, but one 
antibacterial agent prevails. The antibacterial agents within an antibacterial class (Anatomical Therapeutic Classification, ATCvet level 4 or 5; www.WHOcc.no) were summed over the 3-month period for each herd, and the principal antibacterial was identified.

Antibacterial classes were grouped at the fourth or fifth ATC level, according to the official treatment guidelines (see Table 2). For example, all aminoglycosides for oral use were grouped into one class, whereas colistin was kept in a separate class. Across the study herds, the principal antibacterials comprised $80 \%$ and $77 \%$ of the total oral antibacterials prescribed within the 3-month periods before and after the laboratory analysis, respectively.

For each of the four bacterial pathogens, all antibacterial classes were defined as first-choice and second-choice antibacterials according to the official treatment guidelines (Table 2). Third-choice antibacterials were defined as those not recommended in the guidelines (as a first or second-choice antibacterial) for the specific pathogen. In the case of co-infection with L. intracellularis and B. pilosicoli, the first and second-choice antibacterials were the same as for single infections. In the case of co-infection with E.coli, the veterinarian may choose to: 1) treat the pathogen considered to be responsible for the observed symptoms; 2) use two first-choice antibacterials in parallel, thus treating both/all pathogens; 3) use a second-choice antibacterial that may treat both/all infections. It was decided that all antibacterials defined as first-choice antibacterials for one pathogen should also be considered as first-choice antibacterials in the case of co-infections (Ad 1 and 2). Therefore, if both colistin and tiamulin were used to treat a co-infection with E.coli and L. intracellularis, one of them would be defined as the principal antibacterial, and the choice of drug for the herd would be classified as a first-choice antibacterial. In the case of a co-infection with E.coli, tetracyclines were defined as second-choice antibacterials, in addition to those recommended as second-choice antibacterials for both pathogens (Ad 3).

\subsection{Descriptive and Statistical Analysis}


Data cleansing, tabulations and data analysis were performed in SAS® EG 6.1. The data were first analysed descriptively:

\section{Hypothesis 1}

The change in TI ( $\Delta \mathrm{TI})$ from spring 2014 to spring 2015 was calculated for each herd, and the distribution was displayed as a box plot for each diagnosis group (negative, low-grade and moderate-massive). The descriptive analysis showed that the distribution of $\Delta \mathrm{TI}$ within the smaller groups of herds (negative and low-grade) was not significantly different from the normal distribution (Shapiro-Wilks test of normality). However, the $\Delta \mathrm{TI}$ in the large group of herds (moderate-massive) deviated significantly from the normal distribution, and logarithmic, square root, and other transformations did not result in a near normal distribution. Therefore, a one-sided Wilcoxon rank sum test was applied in order to test whether the $\Delta \mathrm{TI}$ in groups of herds with negative lab results were lower than the $\Delta \mathrm{TI}$ in herds with moderate-massive occurrence of the pathogens.

\section{Hypothesis 2}

The choice of principal antibacterials within the 3-month period prior to sample submission was compared to that within the 3-month period following the 2-month lag phase after the last laboratory results in 2014. The choice of principal antibacterial was plotted in a histogram for each combination of pathogens. Statistical analysis of changes in the principal antibacterial was not found to be relevant (cf. Section 3.2). For each herd, the principal antibacterial was defined as the first, second or third choice for each period. The change in antibacterial was subsequently defined as being either compliant or non-compliant with the guidelines. A chi-square analysis was applied in order to test for an association between the level of compliance with the guidelines before laboratory analysis and the change in the level of compliance.

\section{Results}




\subsection{Treatment incidence (Hypothesis 1)}

In this section, the term antibacterial use refers to the prescription of oral antibacterials for treatment in weaner pigs within the 3-month periods of March to May 2014 and March to May 2015, and pigs refers to weaner pigs (up to $30 \mathrm{~kg}$ body weight).

At a national level, the treatment incidence was an estimated $6.88 \mathrm{ADD}_{15} /$ pig produced in MarchMay 2014 and 6.24 ADD 15 /pig produced in March-May 2015 (Figure 1), corresponding to a 9.3\% decrease in TI. In the same period, the crude antibacterial use (in ADD not adjusted for population size) decreased by $8.6 \%$, while the production of weaner pigs increased by almost $1 \%$.

Estimating the herd-level $\mathrm{TI}$ in the study herds gave some outliers up to $\mathrm{TI}=63 \mathrm{ADD}_{15}$ per weaning pig produced (i.e. 63 daily doses per pig within the 52-day production period). This level is most certainly biased, as it corresponds to more than one daily dosage per day for all pigs in the weaning herd. Nineteen outlier herds with between $22 \mathrm{ADD}_{15}$ and $69 \mathrm{ADD}_{15}$ per weaning pig in at least one of the 3-month periods (mostly in 2014) were excluded from this part of the study, as the CHR records for these herds also supported the notion that the results for these herds may be biased. For 17 of the 19 herds, the number of pigs recorded increased significantly (by 41\%-633\%) between 2014 and 2015. As a result, levels in 2015 were within the 5-95\% percentiles of TI [0-11 ADD 15 /weaning pig] for the remaining herds. This supports the idea that the outliers were caused by biased CHR records in the first period (2014). The number of pigs registered in one outlier herd decreased by $75 \%$ from 2014 to 2015 ; in the last outlier herd, the number of pigs registered was very low in both periods.

For the remaining 1,717 herds, the mean TI and percentiles for each group of herds are shown in Figure 1. The estimated decrease in antibacterial use appeared to be larger in the group of herds without the laboratory-confirmed presence of E. coli (F4 or F18), B. pilosicoli or L. intracellularis (negative). However, the variance was large in all three groups. A one-sided Wilcoxon Rank Sum 
Test showed that the difference between the $\Delta \mathrm{TI}$ of the negative group was not significantly larger $(\mathrm{p}=0.08)$ than the $\Delta \mathrm{TI}$ of the group with moderate-massive occurrence of the pathogens.

The total antibacterial use in the 1,717 study herds corresponded to $72.5 \%$ of the national antibacterial use in both periods, and the decrease in crude (unadjusted) antibacterial use corresponded to changes at national level. In the study herds, antibacterial use measured in $\mathrm{ADD}_{15}$ decreased by $8.5 \%$ from spring 2014 to spring 2015 . This was similar to the decrease observed at national level, but the estimated TI of all three groups of study herds was lower than the estimated TI at national level (Figure 1). The main reason for this difference was that the number of pigs recorded in the CHR register in the second quarter overestimated the number of weaner pigs in Denmark by $15 \%$ in 2014 and $26 \%$ in 2015 compared to the number of weaner pigs calculated from national census data and productivity data. The included herds comprised approximately $65 \%$ of the weaners registered in active herds in the CHR in both 2014 and 2015.

\subsection{Choice of antibacterials (Hypothesis 2)}

Multiple submission dates from the same herd were observed for 253 herds. Of these, 83 herds were omitted because more than 3 months had passed between the first submission and last result. This was based on the assumption that a longer period between the first submission and last laboratory result would result in a greater probability of other factors affecting the choice of antibacterial. The final data set comprised 1,653 weaner herds, including 83 herds with negative laboratory results, 102 herds with low-grade occurrence, and 1,468 with moderate-massive occurrence of the pathogens. Across herds, the principal antibacterial in each herd comprised a total of $80 \%$ and $77 \%$ of the total oral antibacterial prescription for GI treatment in weaners over the two observation periods. In each observation period, the principal antibacterial made up $100 \%$ of oral antibacterial use in more than half of the herds.

Figure 2 shows a comparison of the principal antibacterials before and after diagnosis for each laboratory diagnosis category. For all categories, tetracyclines were the most frequently used 
principal antibacterial both before and after laboratory analysis, despite not being recommended as a first choice for any of the four infections.

Table 3 shows changes in the choice of antibacterial category before and after laboratory diagnosis of moderate-massive occurrence of specific bacteria. In the vast majority of herds, the category of antibacterial was maintained (corresponding to the diagonal categories in Table 3). This number was significantly higher than expected from random distributions $\left(\chi^{2}=1214, p<0.001\right)$, which shows that the probability of maintaining the same category is statistically higher than the probability of changing.

Among the herds that received a third-choice antibacterial before laboratory analyses, $75 \%$ (376/502) continued to use a third-choice antibacterial after the pathogen(s) were identified. In almost all of these herds (371/376), the presence of $E$. coli was confirmed (sometimes together with other pathogens), and this group mainly used tetracyclines or macrolides (304/371).

In the 383 herds that continued with second-choice antibacterials, the vast majority used tetracyclines (65\% of herds before and $48 \%$ of herds after laboratory analyses).

When the submissions tested positive for particular pathogens, compliance with the guidelines was defined as either a change in antibacterial agent towards a first-choice antibacterial, or the continued use of a first-choice antibacterial. In addition, the use of a second-choice antibacterial could be considered compliant if a third- or second-choice antibacterial was previously used. Finally, discontinuing the treatment and managing herd issues using other methods would also comply with the general principles of the guidelines. In contrast, a change from using either no antibacterials or first-choice antibacterials to using second or third-choice antibacterials, or changing from second to third-choice antibacterials, or maintaining a third-choice antibacterial would all be considered noncompliant. 
According to this definition, 582 herds of the 1,468 herds with moderate-massive amounts of the pathogens did not comply with the guidelines after the laboratory analyses (yellow area in Table 3). Nevertheless, there was a marginal increase in the number of herds receiving first-choice antibacterials or discontinuing treatment (increasing from 423 to 462 herds). The proportion of herds going against the guidelines among those that previously complied (according to subsequent findings) was $21 \%$. The relative risk of acting in accordance with the guidelines (Table 3 ) for those who previously complied with the recommendations was 3.1 ( $<<0.001$; 95\% CI: [2.7-3.7]). Conversely, the proportion of herds that did not comply with the guidelines among those previously receiving a third-choice antibacterial was 0.76 . The relative risk of non-compliance after the laboratory results for those previously using third-choice antibacterials was $R R=3.5(p<0.001$; 95\%CI: [3.1-4.0]).

The prescription patterns of the 102 herds with a low-grade occurrence of the pathogens were generally similar to those in herds with a moderate-massive occurrence: second and third-choice antibacterials made up two thirds of principal antibacterials both before (69/102) and after (71/102) laboratory analyses. Prior to the laboratory analysis, 16 herds received no antibacterials for oral use, but five of these herds initiated oral antimicrobial use after laboratory analysis. In contrast, one herd discontinued antibacterial treatment after laboratory analysis showed low-grade occurrence.

The majority of the 83 herds in which none of the four pathogens were identified used antibacterials, mainly tetracyclines (32/83 herds after laboratory analyses; Figure 2). Prior to submission, oral antibacterials were not prescribed in 20 of the 83 herds, which increased to 23 herds following the laboratory results. Only 14\% (9 herds) of the 63 herds that used antibacterials prior to submission discontinued the medication. Conversely, $30 \%$ (6 herds) of the 20 herds that did not use antibacterials prior to submission received oral medication after the laboratory analyses. 


\section{Discussion}

Antibacterial prescription patterns are highly variable over time and influenced by numerous clinical, economic and social factors that vary between and within farms, as well as between veterinarians. This study aimed to investigate the potential effect of new legislation imposing mandatory laboratory analysis prior to the antibacterial batch treatment of pigs. Although it is not possible to determine causal relationships in this type of study, it is possible to investigate whether changes (coincidental or causal) in prescriptions may have occurred in temporal and causal relation to the legislation. The main objectives of the new legislative Order 334/2014 were to support evidence-based prescriptions (i.e. to ensure that a bacterial infection is actually present in cases of batch medication), to ensure that the antibacterial of choice is directed at the actual pathogen, and to support the consideration of differential diagnosis and the alternative management of disease.

Oral antibacterial medication of weaner pigs (measured in ADD) decreased by $8.6 \%$ from spring 2014 to spring 2015. Across the study herds, prescriptions decreased by $8.5 \%$ in March-May 2015 compared to the same period in 2014 (i.e., very close to the decrease observed at national level). Furthermore, antibacterial use in the study herds amounted to approximately $73 \%$ of the national use in both periods, supporting that the study herds may be considered representative of the population. Nevertheless, it is possible that a minority of the herds (i.e. those submitting to other laboratories) may exhibit different patterns. As bacterial pathogens were detected in the vast majority of the study herds, it is unlikely that the general decrease in oral antibacterials observed nationally was caused by the mandatory laboratory analyses. It is more likely that the lowered threshold of the Yellow Card Initiative imposed from $28^{\text {th }}$ February 2014 contributed to the decrease (Anonymous, 2014b).

Previous findings (Pedersen et al., 2015) have indicated that the clinical importance of low-grade infection was questionable; non-bacterial causalities were considered likely in diarrhoeal outbreaks 
(designated low-pathogen outbreaks) where only a small number of pigs in the batch experienced a bacterial intestinal disease (Pedersen et al. 2014).

A low specificity of 0.60 and a high sensitivity $=0.96$ have been found for bacterial pathogenic load (qPCR) as a criteria for identifying diarrhoea with bacterial aetiology (Pedersen et al., 2014). In accordance with this, we found that the pathogens can be present in moderate-massive amounts without associated antibacterial batch treatment: in herds with moderate-massive occurrence of the pathogens, the proportion that did not receive batch treatment varied between $10-20 \%$ depending on the diagnosis group. In particular, the proportion increased in groups of herds where only L. intracellularis (up to $22 \%$ ) or B. pilosicoli (up to $24 \%$ ) were identified in the laboratory. Our findings suggest that the bacteria may not cause diarrhoea in a large proportion of herds, despite the moderate-massive load of the pathogens.

Moderate-massive loads of at least one of the pathogens E.coli, (F4 and F18), B. pilosicoli and L. intracellularis were found in $89 \%$ of the study herds by PCR analyses, while none of the four pathogens were detected in $5 \%$ of the herds. When pathogenic bacteria were detected, there was no increased incentive to discontinue antibacterial treatment. Accordingly, the decrease in antibacterial use per pig from spring 2014 to spring 2015 tended to be more prominent (non-significant, $\mathrm{p}=0.08$ ) in the group of herds where no pathogen was identified. These findings support the view that disease occurrence was lower in the group with negative laboratory diagnosis, or that it was possible to manage disease by means other than antibacterial treatment in some of the herds. This is in accordance with the intention of the legislation. However, the finding is not statistically significant and must be interpreted with caution due to the bias of the denominator (the number of pigs at herd level). The most valid data on the number of live pigs at national level are from Statistics Denmark, and are based on decennial total counts and extrapolation based on index herds. These have a high level of agreement (>99\%) with estimates of live pig numbers based on 
productivity, production and export data (Jensen et al., 2014). Comparison to these data indicated an increasing overestimation of the number of pigs registered in the CHR. As a consequence, the TI calculated at herd level in the present study was most likely underestimated, and the estimated average decrease in TI was likely to be overestimated. Accordingly, antibacterial use decreased between 2014 and 2015 by $1.1 \mathrm{ADD}_{15}$ /pig produced in the study herds, compared to $0.64 \mathrm{ADD}_{15}$ /pig produced at national level (Figure 1). Nevertheless, we have no reason to believe that the increasing overestimation of the number of pigs varied depending on the laboratory diagnoses (i.e. between the three groups of pig herds). We therefore consider the trend towards a larger decrease in antibacterial use in herds with a negative diagnosis may be real.

When only a small proportion of the pigs are diarrhoeic and the bacterial load is low, it is unlikely that the bacteria are causing the diarrhoeal outbreaks in the herds, and such outbreaks should probably be solved by other interventions (Pedersen et al., 2014). Low bacterial load (<35,000 or $10^{4.5}$ per gram faeces) identified by qPCR was found to have a high specificity for identifying lowpathogen diarrhoea (Pedersen et al., 2014). In our study, the criteria for identifying low pathogen load were only slightly different, as the pathogen load was measured for the individual pathogens. No bacterial pathogens were identified in 83 herds (5\%), and a low pathogen load was found in 102 $(6 \%)$ of 1,653 herds. It is possible that some of these findings were due to an inappropriate sampling procedure, or some herds could have a positive diagnosis of GI bacterial pathogens from another laboratory. However, the proportion of herds with diarrhoeal outbreaks, without bacterial pathogens was even higher in a previous study (11\%), although not significantly different from our findings (Pedersen et al., 2015). This may indicate that some of the herds in our study had diarrhoea even though none of the bacterial pathogens were found, and could explain why the majority (150/187) of the herds with negative or low-pathogenic findings continued (or initiated) antibacterial treatment 2-5 months after the laboratory analysis, despite this not being the most appropriate intervention, at least at the time of sample submission. In herds with low-pathogenic 
diarrhoea, Pedersen et al. (2015) found changes in aetiology in the majority of herds within 4-8 weeks, and only $16 \%$ of herds (95\%CI: $0.05-0.36)$ displayed the same infection over three consecutive diarrhoeal outbreaks. This may also explain the continued use of antibacterials in herds with low levels of pathogenic bacteria in our study.

The most common laboratory finding was E. coli (F4 and F18), identified in 55\% of the herds. This is in accordance with a previous study (Pedersen et al., 2015), where E.coli (F4 and F18) was identified in $61 \%(22 / 36)$ of the herds. In addition, E.coli was identified in $62 \%$ of the herds with moderate-massive occurrence of the pathogens, most frequently as the only pathogen $(26 \%$ of the herds), or as a co-infection with L. intracellularis (19\% of the herds). In herds with these two diagnoses, tetracyclines were by far the most common principal antibacterial before and after laboratory diagnosis (37\% increasing to $39 \%$ of the herds). This was surprising, as tetracyclines are third-choice antibacterials for the treatment of E.coli infections due to the frequent occurrence of tetracycline resistance in pathogenic E. coli according to the official guidelines (64\% of E.coli O149 were tetracycline resistant in 2006-2008; Anonymous, 2016a). Preliminary results from the Laboratory for Pig Disease (part of the Danish Pig Research Centre, SEGES P/S) suggested that the level of resistance in E. coli O149, O138, O139, and O141 was at the same level in the periods 2014-2015 and 2006-2008 (Data from Laboratory for Pig Disease (SEGES P/S); Svensmark B., personal communication, 2015). It is likely that antibacterial resistance testing was performed in some of the herds, yet the frequent use of tetracyclines suggests that they were used in some herds with tetracycline-resistant pathogenic E.coli.

Only minor changes in the choice of principal antibacterials were observed across herds. These occurred in $28 \%$ of the herds, of which only $14 \%$ exhibited a shift towards higher compliance with the guidelines. This was much lower than expected from a previous study (Pedersen et al. 2015), in which antibacterial treatment was changed in $63 \%$ of the herds, and for $32 \%$ (18-50\%) of the herds, 
the veterinarian indicated the change was a response to the laboratory findings. The differencebetween in the two studies in respect to responses to laboratory resuls could be due to different motivation for participation/submission of samples: The subsample of veterinarians responsible for the 36 herds in the Pedersen et al. (2015) study were likely to be more motivated for using the laboratory results because the herds represents a minority and the participation was voluntary.

In our study, the herds that complied with the guidelines prior to laboratory analysis were more likely $(\mathrm{RR}=3.1(\mathrm{p}<0.001 ; 95 \% \mathrm{CI}:[2.7-3.7])$ to comply with the guidelines after laboratory analysis. However, a surprisingly high proportion $(21 \%)$ of the herds that complied with the guidelines prior to laboratory analysis subsequently made a shift in antimicrobial choice that went against the guidelines.

The recommended first-choice antibacterials were rarely the principal antibacterial before or after laboratory analysis. Only in the case of a single infection with B. pilosicoli did the proportion of herds using pleuromutilins as first-choice antibacterials increase considerably (from $4 \%$ to $15 \%$ of the herds). The reason could be a general underestimation by veterinarians of the herd-level occurrence of B. pilosicoli in particular, as suggested in the previous study (Pedersen et al., 2015). A decrease in the use of tetracyclines as principal antibacterials was almost exclusively observed in the diagnosis groups involving B. pilosicoli (including co-infections), yet tetracyclines remained the most frequently used antibacterials, even for B. pilosicoli. In general, tetracyclines remained the most frequently chosen principal antibacterial, irrespective of laboratory diagnosis, despite not being a recommended agent for the treatment of infection with any of the four pathogens. In the official guidelines, tetracyclines are second-choice antibacterials for the treatment of diarrhoea caused by L. intracellularis and B. pilosicoli. 
A driving factor in the high proportion of herds using tetracyclines may be the broad spectrum of tetracyclines, as they are reasonably effective against all four pathogens (with the exception of E.coli carrying tetracycline-resistance genes). Furthermore, cost is a motivating factor affecting antibacterial prescription in the pig sector, and a previous study showed that the cost of a cure dosage of tetracyclines was lower than for other antibacterials (except tiamulin) in Denmark between 2005 and 2010 (Anonymous, 2009; Anonymous, 2010; Sheehan 2013). The costeffectiveness of antibacterial treatment compared to preventive interventions may also be important. In addition, pressure and the level of compliance from the farmer may influence the veterinarian's choice of antibacterial (Coyne et al., 2014). Pedersen et al. (2015) found an agreement of only 0.18 (95\%CI: 0.08-0.34) between veterinarians' diagnosis at sampling and the laboratory diagnosis. In particular, the occurrence of $L$. intracellularis in the herds was highly overestimated by the veterinarian compared to the laboratory diagnoses. Such uncertainty regarding diagnoses could partially explain the frequent use of broad-spectrum tetracyclines prior to laboratory analysis in the present study, yet it cannot explain the continued use of third-choice antibacterials after the diagnosis.

\section{Conclusion}

The use of oral antibacterials in weaner pigs decreased by $8.6 \%$ on a national level in spring 2015 compared to spring 2014. It is likely that this is due to factors other than the mandatory laboratory testing (e.g. the lowered threshold of the Yellow Card Initiative imposed from $28^{\text {th }}$ February 2014). The use of antibacterials tended to decrease more in herds with no confirmed presence of the pathogens, although this was not significant and possibly due to bias. Whether there is a causal relationship with the mandatory laboratory testing cannot be determined from this study. Tetracyclines were the most common antibacterials used for GI disease in weaners, both prior to submission of samples and 2-5 months after laboratory analyses, irrespective of which intestinal 
pathogen was identified. The choice of principal antibacterial changed towards higher compliance with the guidelines after laboratory analysis in only in a minority of the herds (14\%). Increased compliance was mostly observed after identification of B. pilosicoli. Non-compliance with the guidelines after laboratory analysis was mostly related to the use of tetracyclines in herds with E.coli infections. Furthermore, the risk of non-compliance was significantly higher $(\mathrm{RR}=3.5)$ when a third-choice antibacterial was used prior to laboratory analysis, when compared to all other cases.

The pattern of prescription was almost unchanged across the group of herds with moderate-massive occurrence of E. coli and/or L. intracellularis. Tetracyclines remained the most frequently used antibacterials by a substantial margin for all diagnoses, despite not being first-choice antibacterials according to the official guidelines. However, tetracyclines are effective against $L$. intracellularis. Sensitivity to tetracycline is detected in only one third of $E$. coli isolated from diarrhoea, indicating the need for current $E$. coli sensitivity testing prior to use of tetracyclines.

Between 10-20\% (depending on the diagnosis group) of the herds did not use batch treatment, despite the presence of pathogens in moderate-massive amounts. Further studies are needed to identify other factors affecting the level of disease and the need for antibacterial batch treatment in herds with moderate-massive occurrence of the pathogens.

\section{Funding}

This study was funded by the Danish Food and Veterinary Administration (DFVF), as part of an ongoing project concerning veterinary disease surveillance data. The results were presented and discussed in a project group including two representatives from the DFVF, but they did not interfere in the interpretation, discussion and publication of the results. 


\section{Acknowledgements}

Thanks to Mette Kirkeskov Sie (DVM) and Anna Huda (DVM) from the Danish Food

Administration for supplying information about the National Guidelines on veterinary antibacterial treatment, the CHR register and the current legislation, and for the fruitful discussions.

\section{References}

1. Anonymous 2011. Special provisions for the reduction of the consumption of antibiotics in pig holdings (the yellow card initiative). Danish Veterinary and Food Administration.

www.foedevarestyrelsen.dk/english/SiteCollectionDocuments/25_PDF_word_filer\%20til\%20download/Yell ow\%20Card\%20Initiative.pdf.

2. Anonymous, 2014a. Bekendtgørelse om dyrlægers anvendelse, udlevering og ordinering af lægemidler til dyr (in Danish). Order no. 533 of $27^{\text {th }}$ May 2014. www.retsinformation.dk/Forms/R0710.aspx?id=163425.

3. Anonymous, 2014b._Bekendtgørelse om grænseværdier for antibiotikaforbrug i kvæg- og svinebesætninger (in Danish). Order no. 178 of $26^{\text {th }}$ Feb 2014. www.retsinformation.dk/Forms/R0710.aspx?id=161940.

4. Anonymous, 2014c. Bekendtgørelse om sundhedsrådgivningsaftaler for svinebesætninger (in Danish). Order no. 534 of $27^{\text {th }}$ May 2014. www.retsinformation.dk/Forms/R0710.aspx?id=163427.

5. Anonymous, 2015a: Global Action Plan on Antimicrobial Resistance. World Health Organization. ISBN 978924150976

6. Anonymous, 2015b. Årsrapport 2014 vedrørende laboratorieanalyser af material fra svin på DTU-Vet og Laboratorie for svinesygdomme (SEGES P/S). (In Danish). February 2015, Copenhagen, Denmark. www.vet.dtu.dk/Diagnostik/Aarsrapporter-for-diagnostik_overvaagning_beredskab.

7. Anonymous, 2016a: Evidence-based Prudent Use Guidelines for Antimicrobial Treatment of Pigs. www.foedevarestyrelsen.dk/english/Animal/AnimalHealth/Veterinary_medicine/Pages/Evidence_base d_prudent_use_guidelines_for_antimicrobial_treatment_of_pigs.aspx

8. Anonymous, 2016b. Årsrapport 2015 vedrørende laboratorieanalyser af materiale fra svin på DTU-Vet og Laboratorie for svinesygdomme (SEGES P/S) (in Danish). February 2015, Copenhagen, Denmark www.vet.dtu.dk/Diagnostik/Aarsrapporter-for-diagnostik_overvaagning_beredskab.

9. Burow, E., Simone, C., Tenhagen, B.-A., Käsbohrer, A., 2014. Oral antimicrobials increase antimicrobial resistance in porcine E. coli-A systematic review. Prev. Vet. Med. 113, 364-375.

10. Busani, L., Graziani, C., Franco, A., Di Egidio, A., Binkin, N., Battisti, A., 2004. Survey of the knowledge, attitudes and practice of Italian beef and dairy cattle veterinarians concerning the use of antibiotics. Vet. Rec. 155, 733-738.

11. Callens, B., Persoons, D., Maes, D., Laanen, M., Postma, M., Boyen, F., Haesebrouck, F., Butaye, P., Catry, B., Dewulf, J., 2012. Prophylactic and metaphylactic antimicrobial use in Belgian fattening pig herds. Prev. Vet. Med. 106, 53-62.

12. Chase-Topping, M.E., Gunn, G., Strachan, W.D., Edwards, S.A., Smith, W.J., Hillman, K., Stefopoulou, S.N., Thomson, J.R., 2007. Epidemiology of porcine non-specific colitis on Scottish farms. Vet. J. 173, 353-360. 
13. Coyne, L.A., Pinchbeck, G.L., Williams, N.J., Smith, R.F., Dawson, S., Pearson, R.B., Latham, S.M., 2014. Understanding antimicrobial use and prescribing behaviours by pig veterinary surgeons and farmers: a qualitative study. Vet. Rec. 175, 593-599.

14. DANMAP 2008. Use of antimicrobial agents and occurrence of antimicrobial resistance in bacteria from food animals, foods and humans in Denmark. ISSN 1600-2032

15. DANMAP 2010. Use of antimicrobial agents and occurrence of antimicrobial resistance in bacteria from food animals, foods and humans in Denmark. ISSN 1600-2032

16. DANMAP 2013. Use of antimicrobial agents and occurrence of antimicrobial resistance in bacteria from food animals, food and humans in Denmark. ISSN 1600-2032

17. De Briyne, N., Atkinson, J., Pokludová, L., Borriello, S.P., Price, S., 2013. Factors influencing antibiotic prescribing habits and use of sensitivity testing amongst veterinarians in Europe. Vet. Rec. 173, 475482.

18. Gibbons, J.F., Boland, F., Buckley, J.F., Butler, F., Egan, J., Fanning, S., Markey, B.K., Leonard, F.C., 2013. Influences on antimicrobial prescribing behaviour of veterinary practitioners in cattle practice in Ireland. Vet. Rec. 172, 14-18.

19. Jensen, V.F., de Knegt, L.V., Andersen, V.D., Wingstrand, A., 2014. Temporal relationship between decrease in antimicrobial prescription for Danish pigs and the "Yellow Card" legal intervention directed at reduction of antimicrobial use. Prev. Vet. Med. 117, 554-564.

20. Jessen, O., 2015. National average for productivity in the pig production 2014. Danish Pig Research Centre. Brief no.1523. http://vsp.If.dk/ /media/Files/PDF\%20-

\%20Publikationer/Notater\%202015/Notat_1523.pdf.

21. Merle, R., Hajek, P., Käsbohrer, A., Hegger-Gravenhorst, C., Mollenhauer, Y., Robanus, M., Ungemach, F.R., Kreienbrock, L., 2012. Monitoring of antibiotic consumption in livestock: a German feasibility study. Prev. Vet. Med. 104, 34-43.

22. Pedersen, K.S., Johansen, M., Angen, O., Jorsal, S.E., Nielsen, J.P., Jensen, T.K., Guedes, R., Ståhl, M., Bækbo, P., 2014. Herd diagnosis of low pathogen diarrhoea in growing pigs - a pilot study. Ir. Vet. J. 67, 24-32.

23. Pedersen, K.S., Okholm, E., Johansen, M., Angen, Ø., Jorsal, S.E., Nielsen, J.P., Bækbo, P., 2015. Clinical utility and performance of sock sampling in weaner pig diarrhoea. Prev. Vet. Med. 120, 313-320.

24. Pluske JR, Pethick DW, Hopwood DE, Hampson DJ, 2002. Nutritional influences on some major enteric bacterial diseases of pig. Nutr. Res. Rev. 15, 333-71.

25. Sheehan R., 2013. Summary of UK Veterinary Prescribing Pressures Focus Groups. The Veterinary Medicines Directorate. www.vmd.defra.gov.uk/pdf/Summary_FocusGroups.pdf.

26. Statistics Denmark, 2016. Number of pigs, quarterly figures by type. www.statistikbanken.dk/SVIN

27. Teale, C.J., Moulin, G., 2012. Prudent use guidelines: a review of existing veterinary guidelines. Rev. Sci. Tech. 31, 343-354.

28. Vandeweerd, J.M., Vandeweerd, S., Gustin, C., Keesemaecker, G., Cambier, C., Clegg, P., Saegerman, C., Reda, A., Perrenoud, P., Gustin, P., 2012. Understanding veterinary practitioners' decision-making process: implications for veterinary medical education. J. Vet. Med. Educ. 39, 142-151

29. WHO, 2015. Global Action Plan on Antimicrobial Resistance. World Health Organization 2015; Objective 3 and Objective 4. ISBN 9789241509763 
Table 1. Classification of weaning pig herds based on laboratory testing for gastrointestinal pathogens $^{\mathrm{a}}$

\begin{tabular}{|c|c|c|c|}
\hline \multirow{2}{*}{ Diagnosis group } & \multirow{2}{*}{ Definition } & \multicolumn{2}{|c|}{ Number of herds ${ }^{b}$} \\
\hline & & H1 & $\mathbf{H 2}$ \\
\hline Negative & All samples tested negative for the 4 pathogens & 85 & 83 \\
\hline Low-grade occurrence & $\begin{array}{l}\text { Positive }\left(>10^{3} \text { copies/gram) for at least one }\right. \\
\text { pathogen, less than moderate occurrence of all } \\
\text { pathogens }\end{array}$ & 102 & 102 \\
\hline \multicolumn{4}{|l|}{ Moderate-massive occurrence } \\
\hline ECOLI positive & $>10^{5}$ copies/gram faeces & \multirow{7}{*}{1,530} & 442 \\
\hline BPILO positive & $>10^{4}$ copies/gram faeces & & 46 \\
\hline LAWS positive & $>10^{5}$ copies/gram faeces & & 171 \\
\hline ECOLI and LAWS positive & $\begin{array}{l}\text { LAWS }>10^{5} \text { and/or ECOLI }>10^{5} \text { copies/gram } \\
\text { faeces } \\
\text { Both pathogens }>10^{3} \text { copies/gram faeces }\end{array}$ & & 332 \\
\hline ECOLI and BPILO positive & $\begin{array}{l}\text { BPILO }>10^{4} \text { and/or ECOLI }>10^{5} \text { copies/gram } \\
\text { faeces } \\
\text { Both pathogens }>10^{3} \text { copies } / \text { gram faeces }\end{array}$ & & 94 \\
\hline LAWS and BPILO positive & $\begin{array}{l}\text { BPILO }>10^{4} \text { and/or LAWS }>10^{5} \text { copies/gram } \\
\text { faeces } \\
\text { Both pathogens }>10^{3} \text { copies } / \text { gram faeces }\end{array}$ & & 187 \\
\hline $\begin{array}{l}\text { LAWS, BPILO and ECOLI } \\
\text { positive }\end{array}$ & $\begin{array}{l}\text { BPILO }>10^{4} \text { and/or LAWS }>10^{5} \text { and/or ECOLI }> \\
10^{5} \text { copies/gram faeces } \\
\text { Three pathogens }>10^{3} \text { copies/gram faeces }\end{array}$ & & 196 \\
\hline Total & & 1,717 & 1,653 \\
\hline
\end{tabular}

${ }^{a}$ : Laboratory analysis for GI pathogens: $\mathrm{ECOLI}=E$. coli $; \mathrm{BPILO}=B$. pilosicoli; $\mathrm{LAWS}=L$. intracellularis.

${ }^{\mathrm{b}}$ : Number of herds included for investigation of Hypothesis 1 (H1) and Hypothesis 2 (H2) respectively, after omission of outliers (for $\mathrm{H} 1$ ) and omission of herds with more than 3 months between submission and final laboratory result (H2). 
Table 2. Definition of first- and second-choice antibacterials ${ }^{\mathrm{a}}$ for treatment of diarrhoeal bacterial pathogens

\begin{tabular}{|c|c|c|}
\hline Bacterial pathogen & $\begin{array}{l}\text { First-choice } \\
\text { antibacterial }\end{array}$ & Second-choice antibacterial \\
\hline \multirow{3}{*}{ L. intracellularis } & \multirow{3}{*}{ tiamulin, valnemulin } & tetracyclines, \\
\hline & & lincosamide/spectinomycin, \\
\hline & & macrolides, sulfonamide/trimethoprim \\
\hline \multirow{2}{*}{ B. pilosicoli } & \multirow{3}{*}{ tiamulin, valnemulin } & tetracyclines, lincosamide, macrolides, \\
\hline & & sulfonamide/trimethoprim \\
\hline \multirow{3}{*}{ E. coli } & & aminoglycosides, \\
\hline & \multirow[t]{2}{*}{ colistin } & sulfonamide/trimethoprim, \\
\hline & & aminopenicillins \\
\hline \multirow{3}{*}{$\begin{array}{l}\text { L. intracellularis } \\
\text { B. pilosicoli }\end{array}$} & \multirow{3}{*}{ tiamulin, valnemulin } & tetracyclines, \\
\hline & & lincosamide/spectinomycin, \\
\hline & & macrolides, sulfonamide/trimethoprim \\
\hline \multirow{3}{*}{$\begin{array}{l}\text { L. intracellularis } \\
\text { E. } \text { coli }^{l}\end{array}$} & \multirow{3}{*}{$\begin{array}{l}\text { tiamulin, valnemulin, } \\
\text { colistin }\end{array}$} & tetracyclines, \\
\hline & & sulfonamide/trimethoprim, \\
\hline & & lincosamide/spectinomycin \\
\hline \multirow{3}{*}{$\begin{array}{l}\text { B. pilosicoli } \\
\text { E. } \text { coli }^{l}\end{array}$} & \multirow{3}{*}{$\begin{array}{l}\text { tiamulin, valnemulin, } \\
\text { colistin }\end{array}$} & tetracyclines, \\
\hline & & sulfonamide/trimethoprim, \\
\hline & & lincosamide/spectinomycin \\
\hline \multirow{3}{*}{$\begin{array}{l}\text { E. coli } \\
\text { L. intracellularis } \\
\text { B. pilosicoli }\end{array}$} & \multirow{3}{*}{$\begin{array}{l}\text { tiamulin, valnemulin, } \\
\text { colistin }\end{array}$} & tetracyclines, \\
\hline & & sulfonamide/trimethoprim, \\
\hline & & lincosamide/spectinomycin \\
\hline
\end{tabular}

${ }^{\mathrm{a}}$ For single infections, the definition of first and second choice follows the National Guidelines (Anonymous, 2015a).

For co-infections, the definitions are defined for this study by deduction from the guidelines for single infections, as explained in the text. 
Table 3 Classification ${ }^{\text {a }}$ of principal antibacterial choice at herd level before and after laboratory identification of moderate-massive amounts ${ }^{\mathrm{a}}$ of the pathogens

\begin{tabular}{|c|c|c|c|c|c|c|}
\hline \multirow{7}{*}{ 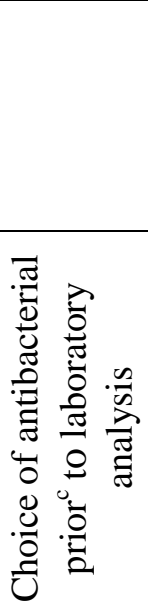 } & \multirow[b]{4}{*}{ None } & \multicolumn{4}{|c|}{$\begin{array}{c}\text { Choice of antibacterial } \\
\text { following }{ }^{\mathrm{b}} \text { laboratory analysis }\end{array}$} & \multirow[t]{2}{*}{ Total } \\
\hline & & None & $1 \mathrm{st}$ & 2nd & $3 r d$ & \\
\hline & & \multicolumn{4}{|c|}{ Number of herds (\%) } & \\
\hline & & $109(7)$ & $10(1)$ & $60(4)$ & $46(3)$ & $225(15)$ \\
\hline & $1 \mathrm{st}$ & $19(1)$ & $122(8)$ & $39(3)$ & $18(1)$ & $198(13)$ \\
\hline & 2nd & $47(3)$ & $70(5)$ & $383(26)$ & $43(3)$ & $543(37)$ \\
\hline & $3 \mathrm{rd}$ & $45(3)$ & $40(3)$ & $41(3)$ & $376(26)$ & $502(34)$ \\
\hline & Total & $220(15)$ & $242(16)$ & $523(36)$ & $483(33)$ & 1,468 \\
\hline
\end{tabular}

${ }^{\text {a } A c c o r d i n g ~ t o ~ o f f i c i a l ~ g u i d e l i n e s: ~ t h e ~ p r i n c i p a l ~ a n t i b a c t e r i a l ~ d e f i n e d ~ a s ~ f i r s t, ~ s e c o n d ~ o r ~ t h i r d ~ c h o i c e ~ a c c o r d i n g ~ t o ~ T a b l e ~ 2 ; ~}$ third choice comprises antibacterials that are not recommended for the treatment of E.coli, B. pilosicoli or L. intracellularis. The shaded area represents changes in antibacterial choice that are non-compliant with the official guidelines.

${ }^{\mathrm{b}}$ Category of principal antibacterial 61-152 days after the results of laboratory analysis.

${ }^{\mathrm{c}}$ Category of principal antibacterial 91 days before submission for laboratory analysis. 


\section{Figure legends}

Figure 1: Herd-level antibacterial use ${ }^{1}$ per weaning pig produced in spring 2014 and spring 2015 within groups of herds with different laboratory findings ${ }^{2}$.

1) Distribution of antibacterial use per pig at herd level within each group of herds: box plot of the mean; bars: $25^{\text {th }}$ and $75^{\text {th }}$ percentiles; lines: $5^{\text {th }}$ and $95^{\text {th }}$ percentiles. Note: the estimated use per pig produced is likely to be underestimated because the number of weaner pigs registered in the CHR overestimates the number of pigs in general. Green lines show the national level for comparison.

2) Laboratory finding of E. coli (F4 and F18), B. pilosicoli or L. intracellularis by PCR.

Figure 2: Choice of antibacterial for oral use ${ }^{1}$ depending on laboratory findings of moderatemassive amounts of the diarrhoeal pathogens ${ }^{2}$.

1: Principal antibacterials for herd treatment. 2: B. pilosicoli, E.coli (F4 or F18) or L. intracellularis. 

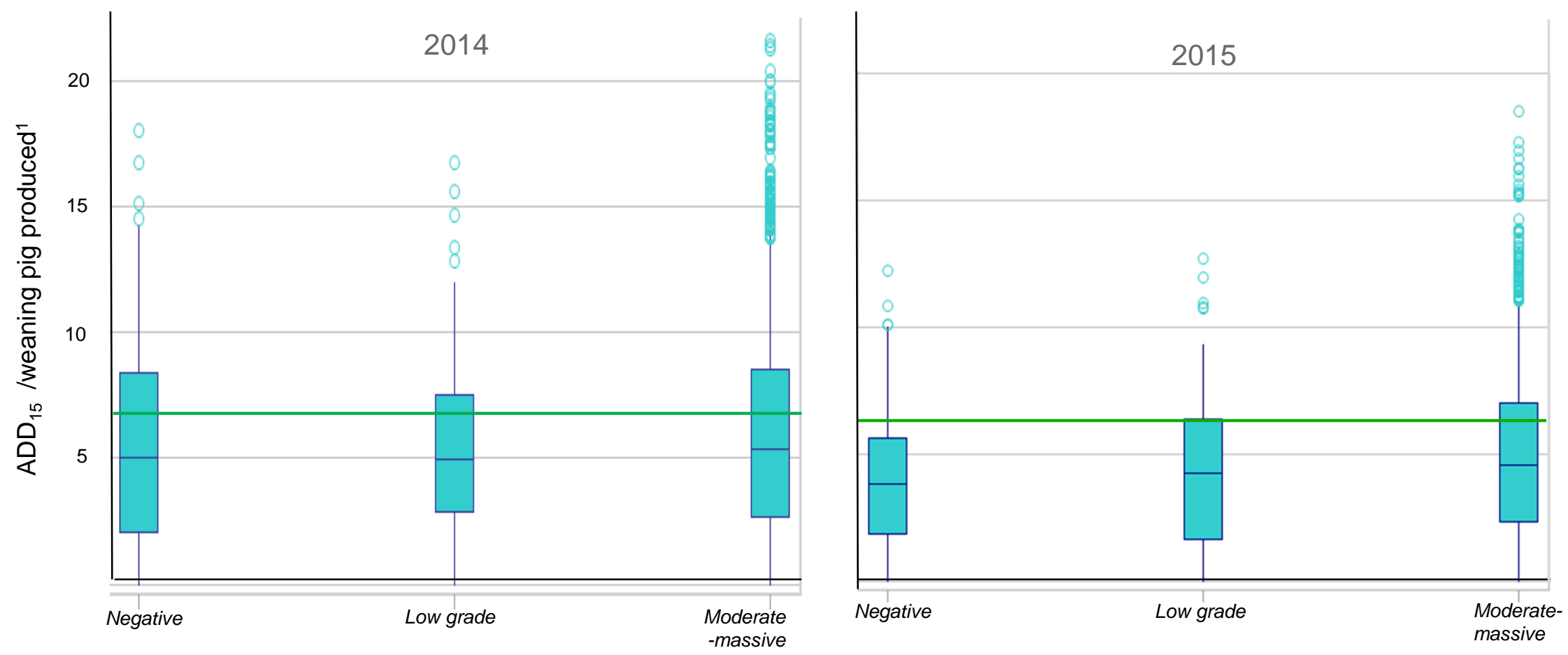

Groups of herds based on laboratory findings 
Figure 2 Choice of antimicrobial for oral use ${ }^{\mathrm{a}}$ depending on laborative findings of moderate-massive amounts of the diarrhoal pathogens ${ }^{b}$
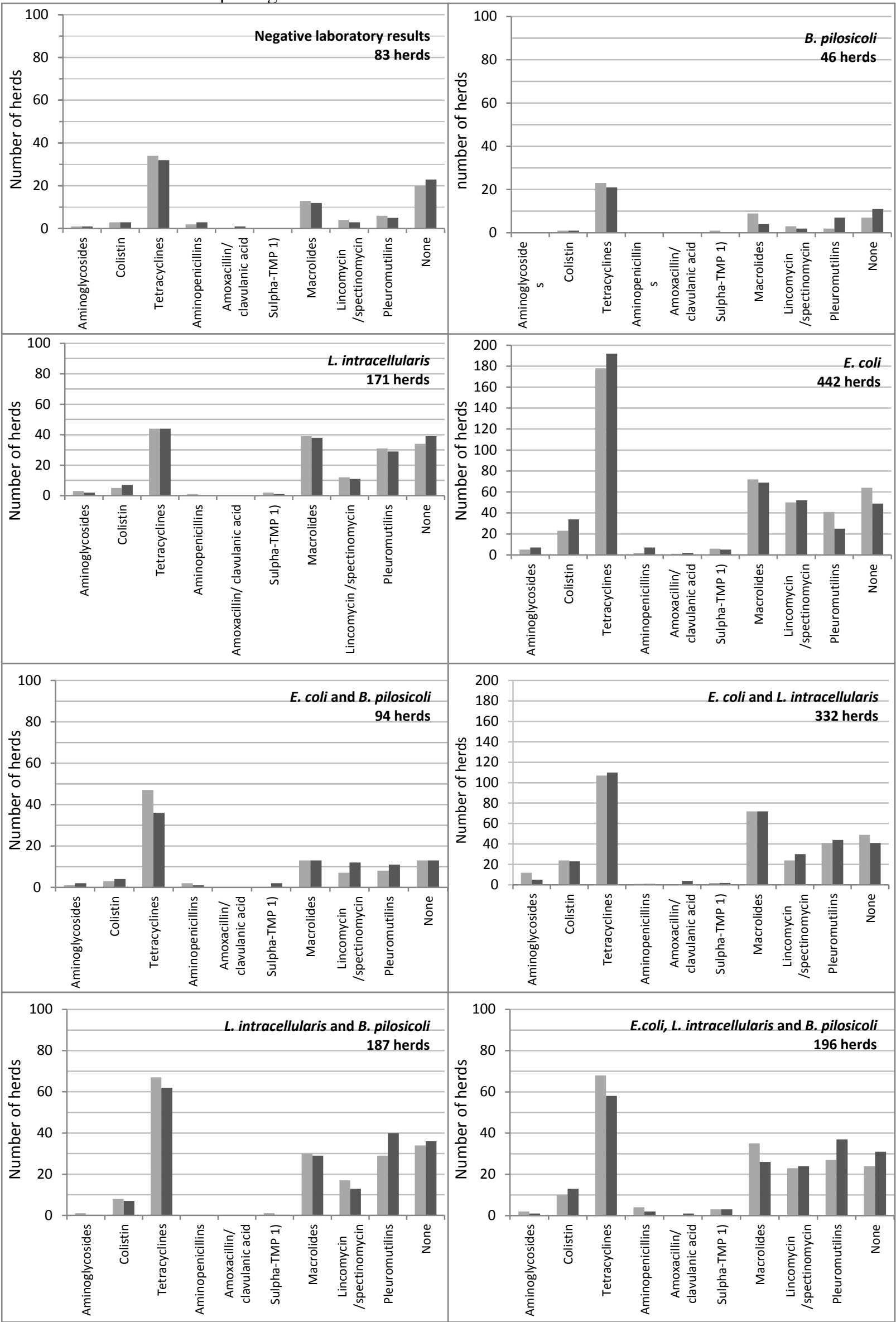

a: Principal antimicrobials for herd treatment. b: B. pilosicoli, E.coli (F4 or F18) or L. intracellularis.

3 months before laboratory analvsis. $\quad 2-5$ months after laboratory analvsis. 